\title{
Pengetahuan Guru PAUD Tentang KPSP (Kuesioner Pra Skrining Perkembangan) Sebagai Alat Deteksi Tumbuh Kembang Anak
}

\author{
Dewi Eko Wati \\ Lecturer FKIP PG PAUD Universitas Ahmad Dahlan Yogyakarta \\ Email: ekowati_dewi@yahoo.co.id
}

\begin{abstract}
Children are a very important part in the survival of a nation. Kids are human resources for the development of a nation, a determinant of the future, and the successor generations of the family and the nation. Therefore, they must be in a healthy condition. Efforts to create a healthy generation should be considered, especially in the golden age (the golden period) that occurs at the age of 0-6 years. Therefore, it is necessary to process the detection and stimulation of growth and development for the creation of the next generation of quality that can grow and develop physically, emotionally, and socially. This study aimed at describing knowledge about early childhood teachers KPSP as a tool for early detection of child development. Subjects in this study amounted to 38 people who already have experiences in teaching in early childhood. The research method used is quantitative research. The research instrument used questionnaires and interviews. Data were analyzed using qualitative descriptive analysis. The results of research on teacher's knowledge of the KPSP showed that $73.7 \%$ of the subjects had heard of KPSP but only $2.6 \%$, or 1 out of 38 men who were able to conclude and give advice on the test results KPSP are certainly capable of performing appropriate testing standards. It shows the teacher's knowledge of the KPSP is low. All respondents stated KPSP needs to be given to children in kindergarten as a tool of detection of child development. In general it can be concluded that the positive attitude of the teachers accept their KPSP for kindergarten children. The obstacle faced by teachers in conducting detection using KPSP is the lack of socialization or information and training on KPSP.
\end{abstract}

Keywords: KPSP, detection tool child growth, PAUD teacher

Abstrak. Anak merupakan bagian yang sangat penting dalam kelangsungan kehidupan suatu bangsa. Anak merupakan sumberdaya manusia bagi pembangunan suatu bangsa, penentu masa depan dan penerus generasi keluarga sekaligus bangsa. Oleh karena itu, mereka harus dalam kondisi yang sehat. Upaya-upaya untuk menciptakan generasi yang sehat perlu diperhatikan terutama pada masa keemasan (golden period) yang terjadi pada usia 0-6 tahun.Oleh karena itu perlu dilakukan proses deteksi dan stimulasi tumbuh kembang demi terciptanya generasi penerus yang berkualitas yang mampu tumbuh dan berkembang baik secara fisik, emosisonal, maupun sosial. Penelitian ini bertujuan untuk mendeskripsikan pengetahuan guru PAUD tentang KPSP sebagai alat deteksi dini tumbuh kembang anak. Subjek dalam penelitian ini berjumlah 38 orang yang sudah memiliki pengalaman mengajar di PAUD. Metode penelitian yang digunakan ialah penelitian kuantitatif. Instrumen penelitian menggunakan angket dan wawancara. Teknik analisis data menggunakan analisis deskriptif kualitatif. Hasil penelitian tentang pengetahuan guru terhadap KPSP menunjukkan bahwa73.7\% subjek pernah mendengar tentang KPSP namun hanya $2.6 \%$ atau 1 dari 38 orang saja yang mampu menyimpulkan dan memberikan 
saran terhadap hasil tes KPSP yang tentu saja mampu melakukan pengetesan sesuai standar.Hal ini menunjukkan pengetahuan guru terhadap KPSP tergolong rendah. Seluruh responden menyatakanKPSP perlu diberikan kepada anak TK sebagai alat deteksi tumbuh kembang anak. Secara umum dapat disimpulkan bahwa sikap guru menerima secara positif adanya KPSP untuk anak TK. Kendala yang dihadapi guru dalam melakukan deteksi menggunakan KPSP ialah kurangnya sosialisasi/informasi dan pelatihan tentang KPSP.

Kata kunci: KPSP, alat deteksi tumbuh kembang anak, guru PAUD

\section{Pendahuluan}

Anak merupakan bagian yang sangat penting dalam kelangsungan kehidupan suatu bangsa. Anak merupakan sumber daya manusia bagi pembangunan suatu bangsa, penentu masa depan, dan penerus generasi keluarga sekaligus bangsa. Oleh karena itu, mereka harus dalam kondisi yang sehat. Upaya-upaya untuk menciptakan generasi yang sehat perlu diperhatikan terutama pada masa keemasan (golden period) yang terjadi pada usia 0-6 tahun (Montessori, 2008). Pada masa ini anak sedang dalam pertumbuhan dan perkembangan yang paling pesat baik fisik, emosional, maupun sosial. Perkembangan dan petumbuhan anak telah dimulai sejak prenatal yaitu sejak dalam kandungan. Pembentukan sel saraf otak, sebagai modal pembentukan kecerdasan, terjadi saat anak dalam kandungan.

Tahap awal perkembangan janin sangat penting untuk pengembangan sel-sel otak. Selanjutnya setelah lahir akan terjadi proses mielinasi dari sel-sel saraf dan pembentukan hubungan antar sel saraf. Keduanya sangat penting dalam pembentukankecerdasan. Makanan bergizi dan seimbang serta stimlasi yang optimal sangat diperlukan dalam proses tersebut. Alangkah sayangnya ketika proses yang luar biasa tersebut sudah dilalui dengan baik namun anak tidak mendapatkan stimulasi yang optimal. Untuk mendapatkan tumbuh kembang yang optimal perlu didukung oleh proses detekesi tumbuh kembang anak sejak dini agar para orang tua dan guru mampu memberikan stimulasi yang tepat untuk anakanak mereka.

Proses deteksi dan stimulasi tumbuh kembang menjadi hal yang tidak boleh dianggap remeh demi terciptanya generasi penerus yang berkualitas yang mampu tumbuh dan berkembang baik secara fisik, emosisonal, maupun sosial. Stimulasi dini adalah kegiatan merangsang kemampuan dasar anak usia 0-6 tahun agar anak mencapai tumbuh kembang yang optimal sesuai potensi yang dimilikinya. Anak usia 0-6 tahun perlu mendapatkan stimulasi rutin sedini mungkin dan terus-menerus pada setiap kesempatan. Stimulasi yang kurang optimal dapat menyebabkan penyimpangan tumbuh kembang bahkan dapat menyebabkan gangguan yang menetap. Stimulasi kepada anak hendaknya bervariasi dan ditujukan terhadap kemampuan dasar anak yaitu: kemampuan gerak kasar, kemampuan gerak halus, kemampuan bicara dan bahasa, kemampuan sosialisasi dan kemandirian, kemampuan kognitif, kreatifitas dan moral-spiritual (Awi, 2015).

Deteksi dini adalah upaya penyaringan yang dilaksanakan untuk menemukan penyimpangan kelainan tumbuh kembang secara dini dan mengetahui serta mengenal faktor-faktorresikoterjadinyakelainantumbuh kembang tersebut. Semakin dini ditemukan penyimpangan maka semakin mudah dilakukan intervensi untuk perbaikannya, sebaliknya bila penyimpangan terlambat diketahui maka intervensi untuk perbaikannya 
lebih sulit dilakukan. Keuntungan lain dari deteksi dini adalah agar tenaga kesehatan mempunyai waktu dalam menyusun rencana danmelakukan tindakan/intervensi yang tepat (Sunaryo, 2007).

Dinas Kesehatan bekerjasama dengan Ikatan Dokter Anak Indonesia (IDAI) telah menyusun berbagai instrumen stimulasi, deteksi dan intervensi dini tumbuh kembang untuk anak umur tiga bulan sampai dengan 72 bulan yaitu dengan kuesioner Pra Skrining Perkembangan (KPSP). Instrumen ini ditujukan bukan hanya untuk tenaga kesehatan di Puskesmas dan jajarannya saja (dokter, bidan, perawat, ahli gizi, penyuluh kesehatan masyarakat, dan tenaga kesehatan lainnya yang peduli anak) tetapi juga untuk petugas sektor lainnya dalam menjalankan tugas melakukan stimulasi dan deteksi dini penyimpangan tumbuh kembang anak. Pengasuh atau guru Pendidikan Anak Usia Dini (PAUD) merupakan salah satu mitra tenaga kesehatan dalam melakukan stimulasi dan deteksi dini penyimpangan tumbuh kembang anak (Depkes, 2006). Adanya pengetahuan tentang deteksi dini dan bagaimana cara menggunakan KPSP yang valid dan mudah diharapkan akan mendorong pengasuh dan guru PAUD untuk aktif melakukan deteksi dengan tepat.

Jumlah Balita di Indonesia sangat besar yaitu 10 persesn dari jumlah penduduk sehingga kualitas mereka perlu mendapat perhatian yang serius yaitu mendapatkan asupan makanan yang penuh gizi, stimulasi dan deteksi tumbuh kembang yang berkualitas sehingga hal-hal yang mengganggu tumbuh kembang bisa diketahui lebih awal untuk selanjutnya dilakukan proses stimulasi maupun intervensi sejak dini.

Kuesioner Pra Skrining Perkembangan (KPSP) merupakan salah satu alat skrining/ deteksi yang diwajibkan oleh Depkes untuk digunakan di tingkat pelayanan kesehatan primer.KuesionerPra Skrining Perkembangan atau disebut KPSP merupakan suatu daftar pertanyaan singkat yang ditujukan kepada para orang tua dan dipergunakan sebagai alat untuk melakukan skrining pendahuluan perkembangan anak usia 3 bulan sampai dengan 72 bulan (Prasida, 2015).

Instrumen ini ditujukan bukan hanya untuk tenaga kesehatan di Puskesmas dan jajarannya saja (dokter, bidan, perawat, ahli gizi, penyuluh kesehatan masyarakat, dan tenaga kesehatan lainnya yang peduli anak) tetapi juga untuk mitra strategis lainnya dalam hal ini adalah pengasuh atau guru Pendidikan Anak Usia Dini (Depkes, 2012).

Tujuan penggunaan KPSP adalah untuk mengetahui apakah perkembangan anak normal atau terdapat penyimpangan. Adapun jadwal pemeriksaan KPSP rutin adalah pada umur $3,6,9,12,15,18,21,24,30,36,42$, 48, 54, 60, 66, dan 72 bulan. Jika anak belum mencapai umur skrining tersebut, ibu diminta datang kembali pada umur skrining yang terdekat untuk pemeriksaan rutin. Misalnya ibu datang ketika bayi berusia 7 bulan, maka ibu diminta datang kembali pada saat bayi berusia 9 bulan (Depkes, 2012).

Interpretasi dilakukan setelah petugas menghitung jumlah jawaban ya dan tidak. Interpretasi hasil KPSP dapat disimpulkan ke dalam tiga kemampuan perkembangan yaitu anak dengan perkembangan sesuai, anak dengan perkembangan meragukan, dan anak dengan perkembangan menyimpang. Setelah mengetahui interpretasi hasil KPSP ada beberapa upaya yang bisa dilakukan oleh orang tua, pengasuh, dan atau guru untuk mengembangkan kemampuan anak.Adapun ketiga kemampuan perkembangan tersebut dapat diuraikan sebagai berikut (Depkes, 2012): Anak dengan perkembangan sesuai Kriteria ini bisa diberikan kepada anak apabila jumlah jawaban ya ada 9-10. Artinya orang tua/pengasuh sudah mengasuh anak dengan baik. Upaya yang harus dilakukan oleh orang tua, pengasuh, dan atau guru selanjutnya ialah melakukan stimulasi sesuai dengan umur dan kesiapan anak, mengikutkan setiap ada Posyandu, dan melakukan pemeriksaan rutin menggunakan KPSP setiap 3 bulan pada anak berumur kurang dari 24 bulan dan setiap 6 bulan pada anak umur 24-72 bulan. 
Kriteria ini bisa diberikan kepada anak apabila jumlah jawaban ya ada 7-8. Artinya orang tua/pengasuh perlu melakukan stimulasi kepada anak lebih sering lagi dan setiap saat. Upaya yang harus dilakukan oleh orang tua, pengasuh, dan atau guru selanjutnya ialah melakukan stimulasi untuk mengatasi penyimpangan/mengejar ketertinggalannya minimal intensif selama 2 minggu, apabila anak sakit segera bawa ke dokter dan tanyakan apakah sakitnya tersebut menghambat perkembangannya, dan melakukan KPSP ulang setelah 2 minggu dengan menggunakan daftar KPSP yang sama pada saat anak pertama dinilai. Apabila usia anak sudah berpindah golongan dan KPSP yang pertama sudah bisa semua maka lakukan KPSP sesuai usia anak.

Kriteria ini diberikan kepada anak apabila jumlah jawaban ya minimal 6 . Upaya yang harus dilakukanoleh orang tua, pengasuh, dan atau guru selanjutnya ialah merujuk ke rumah sakit atau klinik tumbuh kembang anak dengan menuliskan jenis dan jumlah penyimpangan perkembangan misalnya gerak kasar, gerak halus, bicara dan bahasa, sosialisasi dan kemandirian.

Tabel 1. Contoh KPSP untuk anak usia 48 bulan

\begin{tabular}{|c|c|c|}
\hline Pertanyaan & Ya & Tidak \\
\hline \multicolumn{3}{|l|}{ Dapatkah anak mengayuh sepeda roda tiga sejauh sedikitnya 3 meter? } \\
\hline \multicolumn{3}{|l|}{$\begin{array}{l}\text { Setelah makan, apakah anak mencuci dan mengeringkan tangannya dengan baik } \\
\text { sehingga anda tidak perlu mengulanginya? }\end{array}$} \\
\hline \multirow{3}{*}{\multicolumn{3}{|c|}{$\begin{array}{l}\text { Suruh anak berdiri satu kaki tanpa berpegangan. Jika perlu tunjukkan caranya dan } \\
\text { beri anak anda kesempatan melakukannya } 3 \text { kali. Dapatkah ia mempertahankan } \\
\text { keseimbangan dalam waktu } 2 \text { detik atau lebih? }\end{array}$}} \\
\hline & & \\
\hline & & \\
\hline \multicolumn{3}{|l|}{$\begin{array}{l}\text { Letakkan selembar kertas seukuran buku ini di lantai. Apakah anak dapat melompati } \\
\text { panjang kertas ini dengan mengangkat kedua kakinya secara bersamaan tanpa } \\
\text { didahului lari? }\end{array}$} \\
\hline \multicolumn{3}{|l|}{$\begin{array}{l}\text { Jangan membantu anak dan jangan menyebut lingkaran. Suruh anak menggambar } \\
\text { seperti contoh ini di kertas kosong yang tersedia. Dapatkah anak menggambar } \\
\text { lingkaran? }\end{array}$} \\
\hline \multicolumn{3}{|l|}{$\begin{array}{l}\text { Jawab:YA } \\
\text { J ereases } \\
\text { Jawab: TIDAK }\end{array}$} \\
\hline \multirow{2}{*}{\multicolumn{3}{|c|}{$\begin{array}{llcccc}\text { Dapatkah } & \text { anak } & \text { meletakkan } 8 & \text { buah kubus satu persatu } \\
\text { di atas } & \text { yang } & \text { lain tanpa } & \text { menjatuhkan kubus } & \text { tersebut? }\end{array}$}} \\
\hline & & \\
\hline \multicolumn{3}{|l|}{ Kubus yang digunakan ukuran $2.5-5 \mathrm{~cm}$. } \\
\hline \multicolumn{3}{|l|}{ Apakah anak dapat bermain petak umpet, ular naga atau permainan lain dimana ia } \\
\hline \multicolumn{3}{|l|}{$\begin{array}{l}\text { Dapatkah anak mengenakan celana panjang, kemeja, baju atau kaos kaki tanpa di } \\
\text { bantu? (Tidak termasuk memasang kancing, gesper atau ikat pinggang) }\end{array}$} \\
\hline Dapatkah anak menyebutkan nama lengkapnya tanpa dibantu? Jawab TIDAK jika & & \\
\hline ia hanya menyebutkan sebagian namanya atau ucapannya sulit dimengerti. & & \\
\hline
\end{tabular}

Sumber: Depkes (2012) 


\section{Metode Penelitian}

Penelitian ini ialah penelitian kuantitatif.

Subjek dalam penelitian ini adalah mahasiswa

PG PAUD UAD semester 1 dan semester

V yang sudah bekerja sebagai guru PAUD sejumlah 38 orang. Instrumen penelitian menggunakan angket dan wawancara. Teknik analisis data menggunakan analisis deskriptif kualitatif.

\section{Hasil Dan Pembahasan}

\section{Pengetahuan guru terhadap KPSP}

Tabel 2. Hasil uji pengetahuan guru terhadap KPSP

\begin{tabular}{|c|l|c|c|c|c|}
\hline \multirow{2}{*}{ No } & \multicolumn{1}{|c|}{ Pertanyaan } & \multicolumn{2}{c|}{ Ya } & \multicolumn{2}{c|}{ Tidak } \\
\cline { 3 - 6 } & & Frek & \% & Frek & \% \\
\hline 1 & $\begin{array}{l}\text { Saya pernah mendengar tentang KPSP (kuesioner Pra skreening } \\
\text { Perkembangan) }\end{array}$ & 28 & 73.7 & 10 & 26.3 \\
\hline 2 & Saya mengetahui tentang KPSP & 24 & 63.2 & 14 & 36.8 \\
\hline 3 & Saya memahami tentang KPSP & 10 & 26.3 & 28 & 73.7 \\
\hline 4 & Saya melakukan mampu pengetesan KPSP & 5 & 13.2 & 33 & 86.8 \\
\hline 5 & Saya mampu menganalisa hasil test KPSP & 3 & 7.9 & 35 & 92.1 \\
\hline 6 & Saya mampu menyimpulkan hasil test KPSP & 2 & 5.3 & 36 & 94.7 \\
\hline 7 & Saya mampu memberikan penilain terhadap hasil test KPSP & 2 & 5.3 & 36 & 94.7 \\
\hline 8 & $\begin{array}{l}\text { Saya mampu menyimpulkan dan memberikan saran terhadap hasil } \\
\text { test KPSP }\end{array}$ & 1 & 2.6 & 37 & 97.4 \\
\hline
\end{tabular}

Dari hasil analisa tentang kemampuan pengetahuan guru terhadap KPSP secara umum dapat disimpulkan bahwa 73.7\% subjek pernah mendengar tentang KPSP namun hanya $2.6 \%$ atau 1 dari 38 orang saja yang mampu menyimpulkan dan memberikan saran terhadap hasil tes KPSP yang tentu saja mampu melakukan pengetesan sesuai standar. Hal ini menunjukkan bahwa kemampuan penguasaan guru terhadap KPSP sebagai alat deteksi tumbuh kembang anak tergolong rendah. Menurut Bloom (dalam Notoatmodjo, 2010) pengetahuan merupakan hasil dari tahu dan terbentuk setelah seseorang melakukan penginderaan terhadap suatu objek tertentu.
Tingkatan pengetahuan mulai dari tahu, memahami, aplikasi, analisis, sintesis, sampai dengan evaluasi. Artinya kemampuan penguasaan mengetahui sesuatu hal tidak hanya dari salah satu aspek saja tetapi harus tersusun dari enam aspek/tingkatan tersebut.

Adanya pengetahuan yang cukup tentang deteksi dini perkembangan dan bagaimana cara menggunakan instrumen dengan tepat akan mendorong para pengasuh atau guru untuk lebih aktif melakukannya, tepat penggunaannya, tepat interpretasinya, tepat juga intervensinya sehingga tercapai pula tujuan dari pemantauan perkembangan anak.

\section{Sikap guru terhadap KPSP}

Tabel 3 sikap guru terhadap KPSP

\begin{tabular}{|c|c|c|c|c|c|}
\hline \multirow{2}{*}{ No } & \multirow{2}{*}{ Pertanyaan } & \multicolumn{2}{|c|}{ Ya } & \multicolumn{2}{|c|}{ Tidak } \\
\hline & & Frek & $\%$ & Frek & $\%$ \\
\hline 1 & $\begin{array}{l}\text { Menurut saya KPSP perlu diberikan kepada anak TK sebagai alat } \\
\text { deteksi tumbuh kembang anak }\end{array}$ & 38 & 100.0 & & \\
\hline 2 & Menurut saya semua guru TK harus memahami KPSP & 36 & 94.7 & 2 & 5.3 \\
\hline
\end{tabular}




\begin{tabular}{llcccc}
\hline \multirow{2}{*}{ No } & \multirow{2}{*}{ Pertanyaan } & \multicolumn{2}{c}{ Ya } & \multicolumn{2}{c}{ Tidak } \\
\cline { 3 - 6 } & Frek & \% & Frek & \% \\
\hline 3 & Menurut saya semua guru TK harus mampu menggunakan KPSP & 35 & 92.1 & 3 & 7.9 \\
& $\begin{array}{l}\text { Menurut saya KPSP harus diberikan diawal anak masuk sekolah } \\
\text { (TK) }\end{array}$ & 38 & 100.0 & & \\
\hline
\end{tabular}

Dari hasil analisis tentang sikap guru terhadap KPSP dapat diketahui bahwa 100\% atau sejumlah 38 orang menyatakan bahwa KPSP perlu diberikan kepada anak TK sebagai alat deteksi tumbuh kembang anak. Secara umum hasil analisa bergerak dari 94.7\% sampai dengan 100\% menganggap bahwa KPSP sangat penting untuk para guru PAUD. Guru PAUD harus mampu memahami dan menggunakan KPSP sebagai alat deteksi tumbuh kembang anak. Hal ini sesuai dengan teori sikap dari Notoatmodjo (2010) yaitu sikap memiliki empat tingkatan yaitu mulai dari menerima, menanggapi, menghargai, dan bertanggung jawab. Dari ke empat tingkatan tersebut semua responden menanggapi secara positif terlihat dari prosentase jawaban yang tinggi yaitu diatas $90 \%$ untuk masing-masing pertanyaan.

\section{Kendala yang dihadapi}

kendala yang dihadapi menurut para subjek dalam menggunakan KPSP yaitu belum pernah mengetahui tentang KPSP, belum memahami KPSP, belum pernah melakukan pengetesan dengan KPSP, belum pernah mendapatkan pelatihan dan sosialisasi tentang KPSP.

\section{Kesimpulan}

Pengetahuan guru terhadap alat deteksi tumbuh kembang anak yaitu KPSP tergolong rendah. Hal ini dapat dilihat dari hasil analisa data yang menunjukkan bahwa $73.7 \%$ subjek pernah mendengar tentang KPSP namun hanya $2.6 \%$ atau 1 dari 38 orang saja yang mampu menyimpulkan dan memberikan saran terhadap hasil tes KPSP yang tentu saja mampu melakukan pengetesan sesuai standar.

Sikap guru terhadap KPSP tergolong positif. Artinya guru mampu menerima KPSP sebagai alat deteksi tumbuh kembang anak dan ingin mengimplementasikannya. Hal ini dapat dilihat dari hasil analisa data yang menunjukkan bahwa 100\% atau sejumlah 38 orang menyatakan bahwa KPSP perlu diberikan kepada anak TK sebagai alat deteksi tumbuh kembang anak.

Kendala yang dihadapi guru dalam mengimplementasikan KPSP ialah kurangnya sosialisasi/informasi dan pelatihan tentang KPSP. Hal ini dapat dilihat dari hasil jawaban subjek tentang kendala yang dihadapi yaitu sebagian besar subjek menyatakan kurangnya sosialisasi dan pelatihan tentang KPSP.

\section{Daftar Pustaka}

Departemen Kesehatan. 2006. Tahap Perkembangan Balita, dan Profil kesehatan RI.www. depkes.go.id. Diakses tanggal 10Desember 2015

2012. Pedoman Pelaksanaan Stimulasi, Deteksi \& Intervensi Dini Tumbuh Kembang Anak.www.depkes.go.id. Diakses tanggal 10Desember 2015

Montessori, M. 2008. The Absorbent Mind, Pikiran Yang Mudah Menyerap. Yogyakarta: Pustaka Pelajar.

Notoatmodjo, Soekidjo. 2010. Promosi Kesehatan (Teori dan Aplikasi). Jakarta : RinekaCipta.

Prasida, Dita Wasthu, dkk. 2015. Pengaruh Penyuluhan Tentang KPSP Terhadap Pengetahuan Guru Di Paud Taman Belia Semarang(Jurnal). The 2nd University Research Coloquium 2015. www.jurnal unimus.ac.idDiakses Tanggal 10 Desember 2015 
Sunardi, Sunaryo. 2007. Intervensi Dini Anak Berkebutuhan Khusus. Jakarta: Departemen Pendidikan Nasional

Wijaya, Awi. (Artikel). Pentingnya Stimulasi Dini Tumbuh Kembang Anak. www.surabaya-ehealth.com Diakses tanggal 10 Desember 2015. 